\title{
Genre Analysis of International Conference Paper Abstracts
}

\author{
Djuwari ${ }^{1}$ \\ 1Pendidikan Bahasa Inggris-Universitas Negeri Malang
}

\section{INFO ARTIKEL}

\section{Riwayat Artikel:}

Diterima: 10 Juni 2018

Disetujui: 4 Oktober 2018

\section{Kata kunci:}

Genre analysis

International conference

Discourse community

\author{
Alamat Korespondensi: \\ Djuwari \\ Pendidikan Bahasa Inggris \\ Universitas Negeri Malang \\ Jalan Semarang 5, Malang 65154 \\ Email: djuwari@perbanas.ac.id
}


Tuckman as in (Basthomi, 2006) proposes a guide of writing an abstract as follows: 1) it should be about 150 to 200 words; 2) it is a summary of the article; 3 ) it should be attractive; 4 ) it should be provided with three to five key words. Yet, when asked about what is meant by attractive and why it should be three to five key words, there is no clear or standard criteria for such questions. Another proponent is Rathbone (1985) also in (Basthomi, 2006), suggests a guide of abstract writing but it is stated in another way as follows: 1) it should recount the main points of the text; 2) it serves a report in miniature; 3 ) it resembles a table of contents.

The guide above remains unclear, for instance what is meant by a miniature in writing? In the next explanation, Rathbone also provides a guide especially for the reviewers how to select a good abstract. As stated, the reviewers should use the criteria to select the abstracts by questioning whether the abstract determines such as 1) the nature of the communication, 2) the readers' preference. Yet, this is still confusing such as what is meant by the nature of the communication and how to make an abstract resembling such a nature and what is meant by determining the readers' preference.

The problem in this research is as follows: "How are the linguistic repertoires incorporated into the international conference paper abstracts?" This paper is part of the writer's dissertation which is extracted at the macro-textual level. In this particular part, the writer attempts to describe the rhetorical moves of the abstracts written by the authors of international conference papers. Besides, it also describes the nonlinguistic elements which cover the number of sentences and words both in each abstract and each move of the abstracts.

Genre studies have been conducted by linguists and other professionals in various speech communities and various settings. By various speech communities, a genre analysis is done on the subject of different groups of people who form a community (Richards \& Schmidt, 2013). By various settings, a genre analysis is also done in relation to other disciplines, such as technology, politics, mass media, literature, and applied linguistics. For the applied linguists, a genre-based approach to the study of written texts has the potential to offer a highly relevant medium for seeking a clear level of linguistic knowledge or identifying a clear level of skills as targets for language learning and the syllabus design (MacCarthy, 2001). It can provide a good guide for the linguists to identify the linguistic repertoire and the social action of a genre. It can also reveal a certain pattern such as the move, textual meta-discourse and linguistic realization, modalities, and verbs of process functions (Hyland, 2002). It is argued that any speech community has its own way of language use (Bhatia, 1991). More specifically, Bhatia always emphasizes on the question as the heart of genre studies, e.g., "Why do a speech community use their language they do?" From such argument, a genre study is always related to learning a language with specific purposes. In that case, a genre can also defined as the study of situated linguistic behaviour in institutionalized academic or professional setting (Bhatia, 1991). As a result, knowing the macro-textual elements as well as the micro-textual elements, the teachers and the learners especially of ESP classes can get the benefits. This is due to the effort of genre analysis that is not only on the sentencebased grammars but also organization which contains language functions or language use in the texts and contexts, that is, moving higher to the moves and steps

In connection with Communicative Language Teaching (CLT), Burns in (Candlin \& Mercer, 2001) argued that genre has played its part in revolutionizing narrowly conceived theories of language learning such as grammatical categories into widely theories of language learning, such as notions and functions. Thus, most language teachers would say they no longer equate the learning of a second language with the learning of traditional grammar.

In connection with all the notions and functions or language functions with the linguistic features behind them, it appears that (Halliday, 1964) approaches to language learning and teaching fit well with communicative language teaching. Furthermore, it provides teachers and learners with a means of exploring language use within a framework of cultural and social purpose. In addition, it is obvious that genre-based language theories have their contribution to such a conceptual framework in the sake of inventing language learning and teaching methodologies.

Based on the argument above, it is obvious that when genre analysis is done in the effort of scrutinizing the language structure and its uses or functions, it will contribute to language teachers and learners. To be more explicit, it can be judged that the common pragmatic function of a paper abstract in a certain discourse community is the purpose of expressing the ideas depicted in the full paper in an international conference presentation and publication. Similarly, when a reader or reviewer reads or reviews a paper abstract from the writer who wants to present his ideas, the reader or reviewer will intentionally consider the paper abstract for 
presentation or publication. To sum up, genre foregrounds the influence of surrounding texts and ways of reading on our response to any one text. More specifically, it confirms textually and reading as functions rather than things. A genre analysis situates texts within textual and social contexts, underlining the social nature of the production and reading of texts. In particular, a genre analysis is useful in examining how a community communicates and this interpersonal communication creates structures that affect what else gets said and done and by whom.

Together with the linguistic features behind the texts or communicative events, it is advisable that communicative language teaching should be appropriately implemented in the classroom. The teachers and learners are provided with a means of exploring language use within a framework of cultural and social purpose. Similarly, genre analysis which explores the underlying concepts of the repertoires behind the language being learned by the learners also contributes to both teachers and learners. Thus, genre-based language theories have their contribution to an effort of inventing language learning and teaching methodologies.

Formerly, genre-based approach is started from the effort of achieving two objectives. First of all, it attempts to find how to recognize and understand various types of texts. From this, any genre of any speech community can be identified. Secondly, it is the effort of seeing what is accomplished in different human activities which are based on the production and use of texts as a major issue in genre theory. From these efforts, genre theory is concerned with much more than mere text types and their formal textual features.

As it is described such as in the book Genre and the New Rhetoric (Freedman \& Medway, 1994), the effort is an attempt to identify two major schools of thought within genre studies, namely The North America School and The Sydney School. The former school is based on viewing the concept of genre from a rhetorical tradition. According to Miller as in (Friedman \& Medway, 1994) this concept is inspired by Miller's seminal essay Genre as Social Action. In such instance, genre is conceptualized as 'typified rhetorical actions based on recurrent situations'. For that reason, such school of thought is considered to have led to the North America School of genre. This school of genre is related to a socio-historical concept basing their genre typification on how texts function within a social and interactional context. Most of the materials deal with professional organizations and the language system used in such organizations.

The second school of thought is The Sydney School of Genre. Miller as in (Friedman \& Medway, 1994) describes that this school of genre is based on Halliday's systemic functional linguistics. For that reason, the analysis attempts to primarily put emphasis on formal textual features. Due to this emphasis, it is therefore, the genre analysis attempts to express a more linguistically oriented concept of genre. However, both of these schools are said to be common in terms of the attention paid to the analysis. It is said that both schools pay attention to the roles. One is the role of the social in conceptualizing and understanding genres and the second is the role of context (Friedman \& Medway, 1994).

Based on the description above, genre theory in the North-American tradition locates its understanding of genre in relation to how people, texts and activities interact with each other in order to produce meaning and knowledge for action. According to (Belcher, 1994) the North America School of thought has shed more light on the genre spaces of ESP pedagogy, especially EOP which focuses on the magnitude of professional sites. On the contrary, Sydney school has contributed much to offer genre-based ESP pedagogy, especially EAP. Genre is considered the top-down analysis in which the analysis started from top-down theory, contextualized, sociorhetorical view of discourse.

ESP has in its brief history adopted various approaches to text analysis. It started from the early register analysis associated with the identification of key grammatical elements of scientific communication (Swales, 1990). Unlike register analysis and rhetorical analysis, the notional/functional approach creates more fruitful method of bringing together lexical items that co-occur naturally. Moving further from register to rhetorical, functional/notional approach is now prevailingly called a genre analysis. By bringing together the insights of the earlier approaches to text analysis, with greater sophistication in the examination of the writers' purpose, genre theory attempts to analyse the higher level of the previous approaches. These macro-textual levels are the moves and steps. According to (Swales, 1990), this approach attempts to marry the textual awareness of the register analysis with a much broader view of how rhetorical considerations govern grammatical choice.

There are some basic concepts of genre analysis. Each genre is differentiated from another as a typified communicative action by having both a socially recognized communicative purpose, and a common characteristic of form. In addition, a communicative purpose is one that is relevant to the community within 
which it is used. According to (Bhatia, 1991), genre repertoires represent a cluster of genres that typically get used. They are useful in revealing the shared knowledge and norms that members of a community have about how to communicate. They give the example, such as in performing a consulting project, a team of consultants interacting with a client may use genres such as a proposal, a work program, progress reports, invoices, and a final report, which together form a genre repertoire for the consulting team. Thus, genre analysis in its most basic form is the process of determining the genres within a given communication. Another description of genre analysis is that by Adam as in (Fludernik, 2000) in merely dialogs and interviews. According to him, beside the linguistic forms, speech acts or language functions can also be found in genres, such as assertion, convincing, directing, prophesying, questioning; excusing; and promising.

According to (Bhatia, 1991), genre analysis has four characteristics. First of all, a genre analysis shows a genuine interest in the use of language to achieve communicative goals. In this sense, it is not an extension of linguistic formalism. Secondly, genre analysis does not represent a static description of language use but gives a dynamic explanation of the way expert users of language manipulate generic conventions to achieve a variety of complex goals. In this sense, it combines the advantages of a sociolinguistics perspective, with those of a cognitive perspective, especially regarding the tactical use of language. Thirdly, it is primarily motivated by applied linguistic concerns, especially language teaching at various levels. Finally, it is narrow in focus but wide in vision, focusing on specific differentiation in language use at various levels of generality.

The characteristics of genre-based approach are identified as the following. According to (Bhatia, 1991), there are at least four distinct: a) Understanding of the specialist code, b) Familiarity with the dynamics of specialist genres, which includes the rhetorical forms and content, c) Specific contexts they respond to and the conventions they tend to use in their responses, and finally, d) A proficiency in the manipulation of specialist genres to respond to the exigencies of unfamiliar and novel situations. In other words, learners need to develop the understanding of code, the acquisition of genre knowledge associated with the specialist culture, sensitivity to cognitive structuring of specialist genres and then, and only then, can they hope to exploit generic knowledge of a repertoire of specialist genres by becoming informed users of the discourse of their chosen field.

(Swales, 1990) found that the abstracts of Sociology research articles are identified as the following: Move 1: Purpose; Move 2: Method-Results; Move 3: Conclusion/ Recommendations. It is clear that the effort of genre analysis will rest at the attempt to uncover the moves, the language functions, and other aspects of language as procedural and social knowledge (Bhatia, 1991). These repertoires, in a specific discourse community, are considered a convention therefore would be beneficial for writing purposes.

There are some previous studies related to genre analysis. First, the study conducted by (Weissberg, 1993), concerning genre study on the graduate seminar paper presentation. He observed 10 seminar presentations, half in each department, and half presented by non-native speakers. The method used in his study was adopted from (Saville - Troike, 1984) analysis of speech event components (i.e., the genre, topic purpose, setting, participants, message form and content, act sequence, and rules for interaction).It shows that

the only non-native speaker of the five observed who used completely conversational style was a Chinese plant generalist. Another finding also showed that the majority of non-native speaker students in this study did not in general covey the "personal" aspect of science inquiry.

The second is the study by (Brett, 1994) focusing on writing. In this research he wanted to see the typical research writing with the samples of 20 research articles of the sociology discipline. The procedure she used is first of all, by classifying the 20 research articles into the construction or general organization such as Introduction, Methods, Results, and Discussion. After this classification, she counted the number of pages of each part using percentage. The average of percentage of the number of pages for Introduction, Methods, Results, and Discussion are 24\%,20\%,40\%, and 16\% respectively. After that, he analysed each part of the organization above based on the communicative functions or speech acts; finally he analysed each based on the linguistic features such as lexical items and grammatical features.

The third is the study by (Vergaro, 2004) focusing on rhetorical differences between Italian and English sales promotion letters. The corpus used consists of authentic materials of the sales promotion letters, 43 Italian and 26 English. English corpus were collected companies during the stay in the UK, some were collected from Italy. It shows that there are differences in the ways in which discourse patterns are organized as well as in the use of mood and modality for the expression of politeness.

The fourth is by (Yoshioka \& Herman, 2000) focusing on genre analysis in the web pages. Herman attempts to provide the process of a tool called the Process Handbook so that the Internet has enabled a way of utilizing 
these genres. He used genre taxonomy representing the elements of both genres and genre systems in terms of purpose, contents, participants, timing of use, place of communicative action, and form including media, structuring devices and linguistic elements.

The fifth study is (Burns, 2001) finding out the language use within a framework of cultural and social purpose. The research was conducted in the classroom with the learners presented the authentic material related to Model of job application letter. The method she used in this classroom research was modelling. This model consists of three steps. First of all, modelling which involved discussion of cultural and social purpose of the genre and the sharing of experience within that context, followed by examples of model text. It was found out that the construction of the job application letter consists of 1) Address, 2) Date, 3) Who to and address, 4) Dear (salutation), 5) Re (about), 6) Main information, 7) Experience, 8) About me (relevant Job, 9) Ending, 10) Reference, 11) Contact, 12) Yours sincerely (complementary close), 13) Signature

The sixth is the study by (Samraj, 2014) on the abstracts of Biology research articles. Using 20 abstracts of the articles of each of subdivisions: Wildlife and Conservation, she found that the moves of these research article abstracts are as the following: Move 1 (Situating the research), Move 2 Purpose, Move 3 (Methods), Move 4 (Results), and Move 5 (Conclusion).

\section{METHOD}

This study employed qualitative research method using text corpus of 45 international conference paper abstracts related to education. These paper abstracts were chosen purposively based on some assumptions (Ary, Jacobs, Razavieh, \& Sorensen, 2002). First, they are written in English by the authors of the conference papers. Second, the papers were, therefore, considered successful to be recommended for international conference presentation and publication in ISBN proceeding. For being successful in this event, the papers as well as the abstracts should undergo blind review by the board of the reviewers of the international conference organization, SEAIR (South East Asia Association of Institutional Research). Third; the reviewers are from Australia, Thailand, and Malaysia. The process of the review started from the abstracts. If the abstract is considered successful, the full papers are subsequently submitted and reviewed. Thus, when the abstract are declined, the paper is automatically impossible for presentation and publication. Based on such rigorous blind review, it is assumed that the abstracts, as writing products, are considered good abstracts. The analysis of this study used the model employed by (Samraj, 2014) of move analysis for the research article abstracts. Based on this model, an abstract consists of five moves: 1) situating the research, 2) purpose, 3) method, 4) results, 5) conclusion. Thus, as (Bhatia, 1991; Swales, 1990) this genre analysis is considered as a genre-based approach which analyses the genre up to the macro-textual level, that is, the rhetorical moves of the abstracts.

\section{FINDINGS AND DISCUSSION}

\section{Findings}

It was found that each sentence in an abstract was assigned to a move. However, in some cases a sentence includes more than one clause. In this sentence, two moves are covered as well, though found only in a few abstracts.

\section{Abstracts and Their Moves (Macro Textual Levels)}

It is found that not all of the abstracts are constructed with five moves such as Move 1 (situating the research), Move 2 (purpose), Move 3 (method), Move 4 (results), and Move 5 (conclusion). Yet, there are some abstracts missing one of the five moves (see Appendix 3, 4, and 5). As shown in Table 1, among the 45 abstracts analysed, 36 abstracts (80\%) are constructed by the authors using Move 1 (situating the research), 45 abstracts (100\%) using Move 2 (purpose), 45 abstracts (100\%) using Move 3 (methods), 43 abstracts (95\%) using Move 4 (results), and 30 abstracts (66\%) using Move 5 (conclusion). In other words, when reiterated in terms of order, it is said that Move 2 of the research is expressed by all the authors of the abstracts in this study (100\%), followed by Move 3 which are expressed by the authors in their abstracts (100\%), then Move 4, that is, $95 \%$, Move 1 , that is, $80 \%$, and Move 5, that is, (66\%). 
T able 1. M oves of the Abstracts

\begin{tabular}{ccc}
\hline Move & $\Sigma$ & Percentage \\
\hline 1. Situating the Research & 36 & $80 \%$ \\
2. Purpose & 45 & $100 \%$ \\
3. methods & 45 & $100 \%$ \\
4. Results & 43 & $95 \%$ \\
5. Conclusion & 30 & $66 \%$ \\
\hline
\end{tabular}

As shown in Table 2, it can be divided into five groups. First of all, $23(51.11 \%)$ abstracts use five moves of 1 , 2, 3, 4, and 5. Secondly, 10 (22\%) abstracts use three moves of 1,2,3, and 4 or abstracts without Move 5. Thirdly, five (11\%) abstracts use Move 2, 3, 4, and 5 or abstracts without Move 1. Fourthly, five (11\%) abstracts use Moves 2, 3, and 4 or abstracts without Move 1 and 5. Last of all, there are two abstracts use Move 1, 2, 3 and 5 or abstracts without Move 4.

T able 2. A bstracts Based on the Construction of the N umber of the M oves

\begin{tabular}{ccccc}
\hline No & Moves & Abstracts No & $\boldsymbol{\Sigma}$ & Percentage \\
\hline 1 & $1,2,3,4,5$ & $1,3,4,5,9,12,13,14,16,17,22,24,26,28,29,31$, & 23 & $51.11 \%$ \\
& & $32,36,39,41,42,44,45$ & \\
2 & $1,2,3,4$ & $11,15,18,20,21,23,33,34,35,38$ & 10 & $22 \%$ \\
3 & $2,3,4,5$ & $6,10,25,27,43$ & 5 & $11 \%$ \\
4 & $2,3,4$ & $7,8,19,30,31$ & 5 & $11 \%$ \\
5 & $1,2,3,5$ & 2,37 & 2 & $4 \%$ \\
& & Total & 45 & $100 \%$ \\
\hline
\end{tabular}

N ote: $M$ ove 1 (Situating the Research); M ove 2 (Purpose); M ove 3 (M ethods); M ove 4 (Results); M ove 5 (Conclusion).

\section{Total Number of Sentences and Words in Each Move of the Abstracts.}

Move 1 appears to be composed of either one, two, three, four, five, or seven sentences. Abstracts with Move 1 can be described as the following. First, among 45 abstracts analysed, four abstracts with one sentence, eleven abstracts with two sentences, eight abstracts with three sentences, five abstracts with four sentences, and finally, only one abstract with seven sentences.

The next result entails the abstracts with Move 2 (purpose) as the following. Among 45 abstracts, 26 abstracts consists of one sentence, 12 abstracts two sentences, five abstracts three sentences.

The following is the abstracts with Move 3 (methods). Among 45 abstracts analysed, 21 abstracts are composed with one sentence, eight abstracts with two sentences, seven abstracts with three sentences, three abstracts with four sentences, two abstracts with five sentences, only one abstract with six sentences, and also one abstract with seven sentences. This variation of the number of sentences make the abstracts have different length and number of the words entailed.

Now, it deals with the abstracts with Move 4 (results). It can be described as follows. First of all, among the 45 abstracts analysed, 22 abstracts are composed with one sentence, 15 abstracts with two sentences, two abstracts with three sentences, four abstracts with four sentences, and three abstracts with five sentences.

Last of all, it deals with the abstracts with Move 5. It can be identified as follows. Among the 45 abstracts analysed, 25 abstracts were composed with one sentence, one abstract with two sentences, two abstracts with three sentences, and two abstract with four sentences.

\section{Abstracts and their total sentences and words.}

This evidence is important for there are different criteria stipulating the number of the words of the abstract? There are different numbers concerning the sentences and words of each abstract. The average number of sentences composed in each abstract is 10.82 sentences (about 11 sentences) while each sentence consists of 17.93 words (about 18 words).

Referring, especially, to the average number of words of each move of the abstracts, it appears so striking when looking at some abstracts and their moves. There are four abstracts with their lengthy Move 1. For example, abstract no 2, in which Move 1 consists of 101 words. In addition, this abstract is without Move 4. When compared to the total number of its words (176 words), it can be seen that Move 1 occupies more than a half of the abstract. 
Another example is abstract no 11 in which Move 1 consists of 114 words but is without Move 5. Thus, Move 1 also spends more than a half number of the total number of the words in this abstract. The next example is abstract no 16. This abstract appears the most striking. Move 1 consists of 140 words, while the total number of the words in this abstract is 217. Again, abstract no 16 also occupies more than half the number of the total number of words in this abstract.

The next is abstract no 40 which also has more words in Move 1, consisting of 109 words. The total number of the words is 215 . It is, therefore, composed of a half the number of the total number of the words in this abstract. Abstract no 44 is also in the same way as abstract no 44. Its Move 1 consists of 119 words while the total number of the words in this abstract is 218 . The same as the previous examples, this abstract has its Move 1 composed of half of the total number of the words in the abstract.

Another move that shows so striking is the only one abstract no 15, in which, its Move 3 is composed of 103 words while the total number of the words of this abstract is 183 . Thus, Move 3 occupies more than half the number of the total number of the words in this abstract. The four abstracts with Move1 deviating from the convention of a discourse community because Move 1 occupies more than a half of the abstract.

In terms of the number of the words the abstract embody, on average each abstract consists of 194 words. When looking at the sentences, the findings are as the following. Move 1, on average, consists of 2.5 sentences (three) sentences or 93 words, Move 2 consists of 1.6 (two) sentences or 75 words, Move 3 consists of 2.2 (could be two or three) sentences or 97 words, Move 4 consists of 1.8 (two) sentences or 79 words, Move 5 consists of 1.4 (two) sentences or 41 words. This evidence appears important for the writer to plan to write an abstract, especially when trying to keep each abstract being efficient and brief.

\section{Discussion of Macro Textual Elements (Moves of the Abstracts)}

The macro textual elements (moves of the abstracts) are described in this discussion in terms of the moves and some features related to the findings such as the moves embodied in each abstracts, the number of sentences in each move, and the total number of the words of each abstract. Based on this specific discussion, the research is supposed to produce a brief description of how well the abstract is designed. In other words, the description in the discussion is directed towards the criteria dealing with the moves of an abstract and the number of the words as in the findings. Here is the description.

\section{Abstracts and Their Moves (Macro Textual Levels)}

There are some points to be asserted in this research in relation to the abstracts and their Moves. First of all, although the findings show that there are some abstracts that not constructed using 5 moves as in Samraj's model, it is evident that 80 per cent of the abstracts analysed are composed of five moves as shown. This also indicates that (Samraj, 2014) argument concerning the importance of providing other moves, especially Move 1 (situating the research) is really reasonable. Thus, the risk without entailing Move 1 in analysing an abstract will be misleading because $80 \%$ of the abstracts analysed prove to be with Move 1 . In the side of the writer, writing an abstract could use Move 1, especially in the discourse community analysed in this research.

However, in treating the abstracts (20\% of them) which are without Move 1, it could be referred to the proponent of genre analysis approach. When it is referred to (Bhatia, 1991)) suggestion, it is stated that writing should be dynamic so that individual style can also be expressed as long as the convention of writing of a certain discourse community is still adopted. This convention can be the obligatory moves in the abstracts (e.g., purpose, methods, and results). In reference to this ad vocation, it can also be referred to (Samraj, 2014) model that an abstract could be composed of five moves: situating the research topic, purpose, method, results, and conclusion. Thus, the three obligatory moves advocated in this research (research evidence) are still adopted or covered in the model of both in (Samraj, 2014; Swales, 1990)

In connection with Move 2, (Samraj, 2014) model, the model as an instrument is also applicable. Using the model by (Samraj, 2014) is still applicable. All of the abstracts or 100 per cents entail the purpose of the research. In other words, all the authors of the international conference paper abstracts write their abstracts using Move 2 (purpose). It can be generalized that the purpose of the research is important in the abstract.

Based on the evidence above, for the writers who want to write an abstract, it is advisable that they take the purpose of the research into consideration. It should be expressed in the abstract after the topic (Move 1). This is supported by the previous studies, (Samraj, 2014; Swales, 1990). This move proves to be obligatory. Thus, the writers who want to write an abstract should also consider such move obligatory in the abstract. Thus, it 
can also be generalized that 95 per cent of the authors of international conference papers write their abstracts by entailing the method of the research because it is important. It is argued that abstracts should entail Move 3 . Therefore, the model employed by (Samraj, 2014) entailing Move 3 is also applicable. However important Move 3 (method of the research) is, some writers tend to combine this move with Move 4 as in (Swales, 1990). Others separate this move from Move 4.

In connection with Move 3 (methods), (Samraj, 2014) argues that this should be separated from the results (Move 4). In this research, it can be seen that there are only three abstracts (abstract no 7, 21, and 34) in which methods and results are combined (like in Swale's model). Here are the examples of combination between methods and results.

Abstract no 7: The result indicated the consistency of the research productivity model and empirical data. The value of Chi-square goodness -of-fit test was 86.30, $\mathrm{df}=72, \mathrm{p}=.119, \mathrm{GFI}=.963$, AGFI=.938, and RMR=.025. The SEM analysis revealed that four variables explained $23.4 \%$ of the variance in research productivity. Research competence and researchers' characteristics are the most direct influential variables towards research productivity. Nevertheless, researchers hip and institutional support for research work were negatively related to research productivity (boldface is mine).

Therefore, it is clear that (Swales, 1990) model combines method-results into one and signifies it as Move 2 (methods-results). It can be seen from the bold typed phrases, e.g., "...The result indicated ..." while in the same move, there are also phrases i.e., "...the research productivity model and empirical data." The next is also indicated by "... of Chi-square goodness..." and so on. This is as indicated in (Swales, 1990) model, which combines methods and results. However, the development of the model by (Samraj, 2014) still provides more applicable model for scrutinizing the moves of the abstracts. The fact is that, there are only three abstracts composed using combination of methods and results in one move.

Evidence that shows a combination of the two moves is, unfortunately, not the same as proposed by (Swales, 1990) that is methods and results. The other evidence shows that there are two abstracts, which combine two Moves into one Move, but it is between purpose and methods (not methods and results as in Swale's model). This happens to be only in abstracts no 15 and 29. Here is the example of such a combination.

Abstract no 15: To support the improvement, we initiated a "four-dimensional-cycle" approach (Four-d-cApproach), including contextual-hierarchy association, Two-way communication method, Theme-based oral English instruction and Activity-integrated skill. To examine the result of metacognitive strategy training, we produced a "Four-dimensional-cycle" oral Communicative Test (standard speech, communicative tactics, crosscultural communication, Pragmatic competence). To pledge "Four-dimensional-cycle" oral Communication to being coming true, "the NTP English Learning Model" (Newly-developed, Two-way-dominated, Performancemutualized), "the SCARF English Teaching Enlightened Procedure" ( $\mathrm{S}=$ Situation, $\mathrm{C}=\mathrm{Content}, \mathrm{A}=\mathrm{Adaptation}$, $\mathrm{R}=$ Reality, $\mathrm{F}=$ Flexibility) and "SLS-focus Infiltration English Teaching Mode" have been in succession designed. (Boldface is mine)

So, it is clear that the bold typed phrases are considered purpose but, by the same token, the methods of analysis used by the researcher in this abstract are stated as well. The most striking one is the lengthy Move 3 (methods) composed by the author of abstract no 15. This abstract has its Move 3 containing four sentences and 103 words while the total number of the words of this abstract is 183 words. For that reason, this abstract has its Move 3 occupying more than a half of the whole abstract.

So far, there is no clear limitation of how many sentences or words an abstract should contain in each of its move. Although there is no statement how many words should one move should contain, according to (Tuckman, 1999), an abstract should be written in brief. It is also stated that an abstract should be composed by the authors reflecting the research articles (RAs) but it should be brief. (Samraj, 2014) states that each move of the abstracts should be written proportionally. However, on such arguments, the wordy move mentioned above shows that the abstract is not good because it spends almost a half of the whole abstract writing. This appears more obvious when viewing the average number of the whole abstracts analysed, that is, 194 words. This means that each move should be about 2 sentences or 38 words.

\section{Abstracts with Five Moves}

In reference to (Samraj, 2014), it is required to employ Move 1 in the analysis. As stated earlier that Move 1 (situating the research) or topic. This is why using Move 1 (situating the research) remains important. Another point in separating Move 3 (methods) from Move 4 (results) provides us more promising idea because 
it is the fact that most abstracts have these two moves separated, albeit only three abstracts are not. Based on the principles asserted by (Samraj, 2014) above, it proves that $22(49 \%)$ of the abstracts are composed by the authors using five moves: Move 1, Move 2, Move 3, Move 4, and Move 5. The results show that $36(80 \%)$ abstracts consist of Move 1 (situating the research topic). In other words, Move 1 (situating the research) is considered prominent.

Another evidence related to the argument for separating Move 3 (methods) from 4 (results). There are 45 (100\%) abstracts which have Move 3 (methods) and 43 (95\%) abstracts signifying Move 4 (results). There is only one abstract, which combines Move 3 and Move 4. Therefore, it is not considered dominant. According to (Bazerman, 1988; Bhatia, 1991), such an abstract is considered to be deviating from the tradition or convention of the speech community. As (Samraj, 2014) stated that Move 3 (methods) should be separated from Move 4 (results), the abstracts that combine Move 3 and Move 4 also seem deviating from the convention of writing a good abstract.

In general, most abstracts analysed use five moves. In addition, Move 1 before Move 2 in writing abstracts is still prominent for being taken for granted that most of the authors of international conference paper abstracts do in this way. This also applies to the idea for separating Move 3 from Move 4 when writing abstracts. Most of the abstracts analysed in this research have these two moves (Move 3 and Move 4) written separately. Thus, the findings are still mostly on conformance with (Bazerman, 1988; Bhatia, 1991; Samraj, 2014).

\section{Abstracts with Moves 2, 3, 4, and 5.}

When considering the types of abstracts, it can be said that this group is the group of abstracts constructed without Move 1 (situating the research). In fact, the number is five abstracts or 11 per cent. (Samraj, 2014) model must be more applicable so that abstracts either with or without Move 1 is still covered. For safety of using the instrument implemented in this research, such model is still versatile, in the sense that any type of abstracts both without and with Move 1 can be treated by the instrument adopted from (Samraj, 2014).

The most striking evidence is that among the whole abstracts, this odd type of abstracts can be said in lower number compared to the findings of the research (Samraj, 2014). An abstract should entail the topic of the research or Move 1 (Samraj, 2014). In general, this type of abstracts has Move 2 (purpose). This Move is employed by the whole authors of the abstracts analysed or 100 per cent of the total abstracts. (Samraj, 2014) still show the same perspective. It is indicated that this move exist in the whole abstracts analysed or 100 per cent have Move 2 (purpose). This proves that the purpose of research must be stated in the abstracts. Yet, when referring to the proponent above, this type of abstracts seems odd because without mentioning the research topic.

\section{Abstracts with Move 2, 3, and 4.}

The type of abstract that is composed by the author without Move 1 (situating the research) and Move 5 (conclusion) appears the same as the type of abstracts without Move 1 (situating the research). There are five abstracts or 11 per cent. However, in regard to (Samraj, 2014) these five abstracts or (11\%) can be justified as a peculiar model of abstracts in this research finding. So, when this model is used for the employment of abstracts writing, it must be inapplicable. Ignoring Move 1 (situating the research) and Move 5 (conclusion) will make an abstract look odd. However, when compared to the other abstracts using Move 1, the number of such abstracts is not big. Thus, it can be said that most of the authors (80\%) entails Move 1 (situating the research topic) and more than half of all of the authors (66\%) include Move 5 (conclusion).

\section{Abstracts with Move 1, 2, 4, and 5.}

The type of abstract ignoring Move 3 (methods), absolutely, appears odd. All of the proponents (Samraj, 2014) suggest that method of the research should be included in the abstract. Without mentioning this move (methods), it is considered deviating from the convention (Bhatia, 1991; Swales, 1990). Even when compared to all of the abstracts analysed, it is obviously strange because there is only one abstract (abstract no 39). It is said to be odd because the previous studies found that Move 3 (methods) is important. (Samraj, 2014; Swales, 1990) consider the importance of Move 3 (methods). Therefore, an abstract without this Move must be vague. However, in this research 43 (95\%) authors of international conference paper abstracts consider methods of the research as important information to be written. 


\section{Abstracts and Their Total Sentences and Words.}

The study provides the evidence that the average number of the sentences of each abstract is 11 sentences while the average number of the words of an abstract is 194 words. (Samraj, 2014) is another proponent who states that an abstract should be composed of 200 words. Unlike (Tuckman, 1999) who stipulated that an abstract consists of 100 to 175 words and Herbert who stipulated an abstract should consist of 200 words. It should be judged that the average number of the words of each abstract found in this research can be used for judging the number of the words that should be embodied in an abstract, that between 175 and 200 words. The average number found here are 194 words.

\section{CONCLUSION AND SUGGESTION}

\section{Conclusion}

This systematic analysis of international conference paper abstracts has increased our understanding of the influence of genre and the text structure. The results of the analysis of the macro-textual level revealed that the Move 2 (results), Move 3 (methods), and Move 4 (results) as part of the abstracts are important. The least but not least is Move 5 (conclusion). Though it is signified by 66\%, it is probable that an abstract should entail this move. Another move is Move 1 (situating the research), as it is signified by $80 \%$ embodied in the abstracts, it can be judged that there is a probability for expressing this move in an abstract.

Concerning the number of the sentences, this research revealed that, on average, an abstract consists of 11 sentences. In terms of the number of the words, each abstract as in this research, consists of 194 words. Therefore, when writing an abstract, it is suggested that it should consist of 150 to 200 words. There is a certainty for the writer to writer each move above in one textual space, though there might be a possibility to combine Move 3 and 4.

\section{Suggestion}

The results of this study, like others on generic variation across disciplines, can be employed in EAP course. Teachers of EAP should draw on findings such as those from this study to inform their students about discursive practices in academic communities in order to facilitate their acculturation into various discourse communities. When teaching their students a new genre, instructors can make the students aware of features that are obligatory in that genre, such as Move 2, Move 3, and Move 4 in the abstract in this study. Students should also be made aware of disciplinary variation in genre structure. By making them acquitted with such a genre, they are equipped with the knowledge of the genre structure as manifested in the moves.

\section{REFERENCES}

Ary, D., Jacobs, L., Razavieh, A., \& Sorensen, C. (2002). Introduction to research in education (6th ed.). Belmont, CA: Wadsworth.

Basthomi, Y. (2006). The rhetoric of article abstracts: A sweep through the literature and a preliminary study. Bahasa Dan Seni, 34(2), 174-189.

Bazerman, C. (1988). Shaping written knowledge: The genre and activity of. Communication in Linguistics-* T.

Belcher, D. (1994). The apprenticeship approach to advanced academic literacy: Graduate students and their mentors. English for Specific Purposes, 13(1), 23-34.

Bhatia, V. K. (1991). A genre-based approach to ESP materials. World Englishes, 10(2), 153-166.

Brett, P. (1994). A genre analysis of the results section of sociology articles. English for Specific Purposes, 13(1), 47-59.

Burns, A. (2001). Genre-based approaches to writing and beginning adult ESL learners. In English language teaching in its social context (pp. 200-207). Routledge, Taylor and Francis Group.

Candlin, C., \& Mercer, N. (2001). English language teaching in its social context: A reader. Psychology Press.

Fludernik, M. (2000). Genres, text types, or discourse modes? Narrative modalities and generic categorization. Style, 34(2), $274-292$.

Friedman, A., \& Medway, P. (1994). Genre and the New Rhetoric. London: Taylor and Francis.

Halliday, M. A. K. (1964). The linguistic sciences and language teaching.

Hyland, K. (2002). Authority and invisibility: Authorial identity in academic writing. Journal of Pragmatics, 34(8), 10911112.

MacCarthy, M. J. (2001). Issues in applied linguistics. Ernst Klett Sprachen.

Richards, J. C., \& Schmidt, R. W. (2013). Longman dictionary of language teaching and applied linguistics. Routledge. 
Samraj, B. (2014). Disciplinary variation in abstracts: The case of wildlife behaviour and conservation biology. In Academic discourse (pp. 50-66). Routledge.

Saville Troike, M. (1984). What really matters in second language learning for academic achievement? TESOL Quarterly, 18(2), 199-219.

Swales, J. (1990). Genre analysis: English in academic and research settings. Cambridge University Press.

Tuckman, B. W. (1999). Conducting education research. United State of America: Harcourt Brace \& Company.

Vergaro, C. (2004). Discourse strategies of Italian and English sales promotion letters. English for Specific Purposes, 23(2), 181-207.

Weissberg, B. (1993). The graduate seminar: Another research-process genre. English for Specific Purposes, 12(1), 23-35.

Yoshioka, T., \& Herman, G. A. (2000). Coordinating information using genres. 